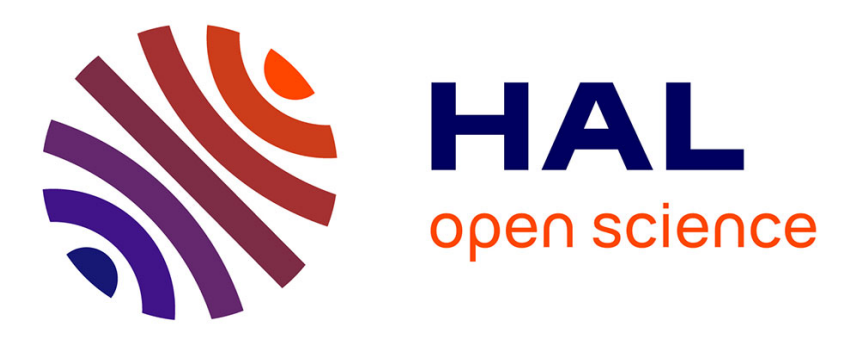

\title{
New linear and quadratic prismatic piezoelectric solid-shell finite elements
}

Fessal Kpeky, Farid Abed-Meraim, El Mostafa Daya

\section{To cite this version:}

Fessal Kpeky, Farid Abed-Meraim, El Mostafa Daya. New linear and quadratic prismatic piezoelectric solid-shell finite elements. Applied Mathematics and Computation, 2018, 319, pp.355-368. 10.1016/j.amc.2017.03.050 . hal-02388830

\section{HAL Id: hal-02388830 \\ https://hal.science/hal-02388830}

Submitted on 2 Dec 2019

HAL is a multi-disciplinary open access archive for the deposit and dissemination of scientific research documents, whether they are published or not. The documents may come from teaching and research institutions in France or abroad, or from public or private research centers.
L'archive ouverte pluridisciplinaire HAL, est destinée au dépôt et à la diffusion de documents scientifiques de niveau recherche, publiés ou non, émanant des établissements d'enseignement et de recherche français ou étrangers, des laboratoires publics ou privés. 


\title{
New linear and quadratic prismatic piezoelectric solid-shell finite elements
}

\author{
Fessal Kpeky ${ }^{a}$, Farid Abed-Meraim ${ }^{a, b^{*}}$ and El Mostafa Daya ${ }^{b, c}$ \\ ${ }^{a}$ LEM3, UMR CNRS 7239, Arts et Métiers ParisTech, 4 rue A. Fresnel, 57078 Metz Cedex 03, France \\ ${ }^{\mathrm{b}}$ Laboratory of Excellence on Design of Alloy Metals for low-mAss Structures (DAMAS), France

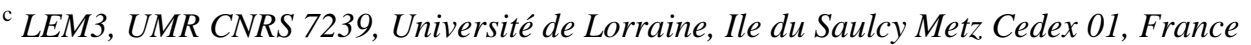

\begin{abstract}
In this work, we propose two prismatic piezoelectric solid-shell elements based on fully three-dimensional kinematics. For this purpose, we perform electromechanical coupling, which consists in adding an electrical degree of freedom to each node of the purely mechanics-based versions of these elements. To increase efficiency, these geometrically three-dimensional elements are provided with some desirable shell features, such as a special direction, designated as the thickness, along which the integration points are located, while adopting a reduced integration rule in the other directions. To assess the performance of the proposed piezoelectric solid-shell elements, a variety of benchmark tests, both in static and vibration analysis, have been performed on multilayer structures ranging from simple beams to more complex structures involving geometric nonlinearities. Compared to conventional finite elements with the same kinematics, the evaluation results allow highlighting the higher performance of the newly developed solid-shell technology.
\end{abstract}

Keywords: Finite elements, Solid-shell, Prismatic geometry, Piezoelectric effect, Vibration analysis.

\section{Introduction}

In recent years, the so-called smart materials have aroused much interest in various fields and industrial applications. These smart materials and the associated devices are nowadays used in vibration control [1-3], shape control [4-6], noise and acoustic control [7-10] as well as in health monitoring of civil infrastructures [11-13]. Predicting the behavior of such materials and structures is therefore crucial for their proper implementation. For this purpose, the numerical simulation represents a very convenient and powerful approach, especially due to its very reasonable cost and its flexibility. Since the early work of Allik and Hughes [14], several tools have been proposed in the literature to model piezoelectric structures. Reviews on mechanical models and finite elements formulations, which can be found in [15-18], reveal that a significant number of $2 \mathrm{D}$ and $3 \mathrm{D}$ piezoelectric finite elements have actually been developed. 
Robbins and Reddy [19] proposed an analysis of piezoelectrically actuated beams using a layer-wise displacement theory. Their work has been extended by Han and Lee [20] as well as by Hwang and Park [21], in order to analyze composite plates with piezoelectric actuators using 2D finite elements based on Kirchhoff's assumptions. Several other authors used Firstorder Shear Deformation Theory (FSDT) and Higher-order Shear Deformation Theory (HSDT), such as in [22-24] and in [25-28], respectively. To enrich the kinematics with respect to the above-discussed works, Kapuria et al. [29-32] introduced the well-known zigzag theory. Interesting contributions to the field were also made by Boudaoud et al. [33], Belouettar et al. [3] and Azrar et al. [34], among others, with applications to vibration control of multilayer structures. From a fundamental perspective, it is important to mention the major theoretical contributions of Weller and Licht $[35,36]$, who studied the asymptotic behavior of thin piezoelectric plates (with or without electric field gradient). All of the above formulations are able to efficiently model beam and plate structures with piezoelectric materials. However, in real-life applications, it is common that relatively thin components coexist with thick structures, such as very thin piezoelectric patch sensors used for the monitoring of civil infrastructures. Consequently, the accurate and efficient modeling of such structures has motivated the development of new finite element technologies, among which the solid-shell concept. In this context also, several finite element models of this type have been proposed in the literature [37-42]. In particular, Sze et al. [37, 38] proposed hybrid finite element modeling of smart structures. In their work, the variation of electric potential was assumed to be linear along the thickness. Their formulation was later extended to the refined hybrid element by Zheng et al. [42]. Alternatively, Klinkel and Wagner [40, 41] assumed in their contributions a quadratic distribution for the electric potential across the thickness. The geometric non-linearities were taken into account, but application of their model was restricted to structures combining elastic and piezoelectric layers. Tan and Vu-Quoc [39] also successfully modeled piezoelectric beam and plate structures under static and vibration conditions. More recently, Kulikov and Plotnikova [43, 44] have developed solid-shell finite elements, which are like most of those developed in the literature, namely having a 2D geometry, while allowing a 3D constitutive law to be considered.

For the motivations described above, and for other well-known technological and practical requirements that have been widely discussed in the literature, the development of solid-shell elements based on three-dimensional kinematics is highly desirable. In this regard, we have recently contributed to this field by proposing linear and quadratic hexahedral piezoelectric solid-shell finite elements, denoted as SHB8PSE and SHB20E, respectively (see Kpeky [45]). These successful formulations of hexahedral piezoelectric solid-shell elements makes necessary the development of prismatic solid-shell elements, in order to easily and automatically model arbitrarily complex structures using free mesh generation tools.

In the current work, we propose to extend the prismatic linear and quadratic solid-shell elements SHB6 and SHB15, formulated in [46, 47], respectively, on the basis of purely mechanical degrees of freedom, to the modeling of structures that contain piezoelectric materials. The remainder of the paper is organized as follows. In Section 2, the coupled electromechanical constitutive equations are presented as well as the discretized problem to 
be solved by the finite element method. Section 3 details the formulation of the SHB6E and SHB15E prismatic piezoelectric solid-shell elements, which are based on linear and quadratic interpolation, respectively. To assess the performance of the proposed piezoelectric solidshell elements, a set of selective and representative benchmark tests are conducted in Section 4 , both in static and vibration analysis. Finally, the main conclusions are summarized in Section 5.

\section{Constitutive equations and discretization of the problem}

\subsection{Electromechanical constitutive equations}

Piezoelectric materials have the capability of generating electricity when subjected to mechanical loading (sensors). Conversely, they also have the ability to deform under electrical charging (actuators). These properties are described by the following coupled electromechanical equations:

$$
\left\{\begin{array}{l}
\boldsymbol{\sigma}=\mathbf{C} \cdot \boldsymbol{\varepsilon}-\mathbf{e}^{T} \cdot \boldsymbol{E} \\
\boldsymbol{D}=\mathbf{e} \cdot \boldsymbol{\varepsilon}+\mathbf{K} \cdot \boldsymbol{E}
\end{array}\right.
$$

where $\sigma$ and $\boldsymbol{\varepsilon}$ represent, respectively, the vector form of the stress and strain tensors; $\boldsymbol{D}$ and $\boldsymbol{E}$ denote the electric displacement and electric field vector, respectively; while $\mathbf{C}, \mathbf{e}$ and $\boldsymbol{\kappa}$ stand for the elastic, piezoelectric and dielectric permittivity matrix, respectively.

The discretized forms $\{\boldsymbol{\varepsilon}\}$ and $\{\boldsymbol{E}\}$ for the strain tensor and the electric field vector are related, respectively, to the discretized displacement $\{\boldsymbol{u}\}$ and to the discretized electric potential $\{\boldsymbol{\phi}\}$, using the discrete gradient operators $\left[\mathbf{B}^{u}\right]$ and $\left[\mathbf{B}^{\phi}\right]$, as follows:

$$
\left\{\begin{array}{l}
\{\boldsymbol{\varepsilon}\}=\left[\mathbf{B}^{u}\right]\{\boldsymbol{u}\} \\
\{\boldsymbol{E}\}=-\left[\mathbf{B}^{\phi}\right]\{\boldsymbol{\phi}\}
\end{array}\right.
$$

In the current contribution, the discrete gradient operators $\left[\mathbf{B}^{u}\right]$ and $\left[\mathbf{B}^{\phi}\right]$ are obtained by finite element discretization for each of the proposed prismatic piezoelectric solid-shell formulations SHB6E and SHB15E, as will be detailed in Section 3.

\subsection{Discretized problem}

The variational principle pertaining to piezoelectric materials, which provides the governing equations for the associated boundary value problem, is described by the Hamilton principle [14]. In this weak form of equations of motion, the Lagrangian and the virtual work 
are appropriately adapted to include the electrical contributions, in addition to the more classical mechanical fields

$$
\begin{aligned}
& -\int_{V} \rho \ddot{\boldsymbol{u}} \cdot \delta \boldsymbol{u} d v-\int_{V} \boldsymbol{\sigma} \cdot \delta \boldsymbol{\varepsilon} d v+\int_{V} \boldsymbol{f}_{v} \cdot \delta \boldsymbol{u} d v+\int_{S} \boldsymbol{f}_{s} \cdot \delta \boldsymbol{u} d s+\boldsymbol{f}_{p} \cdot \delta \boldsymbol{u} \\
& =-\int_{V} \boldsymbol{D} \cdot \delta \boldsymbol{E} d v+\int_{V} \boldsymbol{q}_{v} \cdot \delta \boldsymbol{\phi} d v+\int_{S} \boldsymbol{q}_{s} \cdot \delta \boldsymbol{\phi} d s+\boldsymbol{q}_{p} \cdot \delta \boldsymbol{\phi}
\end{aligned}
$$

where $\rho$ is the material density; $\boldsymbol{q}_{v}, \boldsymbol{q}_{s}$ and $\boldsymbol{q}_{p}$ denote volume, surface and point charge, respectively; while $\boldsymbol{f}_{v}, \boldsymbol{f}_{s}$ and $\boldsymbol{f}_{p}$ represent volume, surface and point force, respectively.

The finite element discretization of the boundary value problem governed by Eq. (3) generally leads to the following system of discretized equations:

$$
\left\{\begin{array}{r}
{\left[\mathbf{M}^{u u}\right]\{\ddot{\boldsymbol{U}}\}+\left[\mathbf{K}^{u u}\right]\{\boldsymbol{U}\}+\left[\mathbf{K}^{u \phi}\right]\{\boldsymbol{\phi}\}=\{\boldsymbol{F}\}} \\
{\left[\mathbf{K}^{\phi u}\right]\{\boldsymbol{U}\}+\left[\mathbf{K}^{\phi \phi}\right]\{\boldsymbol{\phi}\}=\{\boldsymbol{Q}\}}
\end{array}\right.
$$

where all matrices and vectors involved in Eq. (4) are explicitly defined in Tab. 1.

Table 1. Explicit forms for the matrices and vectors resulting from the electromechanical coupling.

\begin{tabular}{ll}
\hline$\left[\mathbf{M}^{u u}\right]=\int_{V}\left[\boldsymbol{N}^{u}\right]^{T} \rho\left[\boldsymbol{N}^{u}\right] d v$ & Mass matrix \\
{$\left[\mathbf{K}^{u u}\right]=\int_{V}\left[\mathbf{B}^{u}\right]^{T}[\mathbf{C}]\left[\mathbf{B}^{u}\right] d v$} & Stiffness matrix \\
{$\left[\mathbf{K}^{\phi \phi}\right]=-\int_{V}\left[\mathbf{B}^{\phi}\right]^{T}[\mathbf{K}]\left[\mathbf{B}^{\phi}\right] d v$} & Dielectric matrix \\
{$\left[\mathbf{K}^{u \phi}\right]=\int_{V}\left[\mathbf{B}^{u}\right]^{T}[\mathbf{e}]^{T}\left[\mathbf{B}^{\phi}\right] d v ;\left[\mathbf{K}^{\phi u}\right]=\left[\mathbf{K}^{u \phi}\right]^{T}$} & Piezoelectric coupling matrix \\
$\{\boldsymbol{F}\}=\int_{V}\left[\boldsymbol{N}^{u}\right]^{T}\left\{\boldsymbol{f}_{v}\right\} d v+\int_{S}\left[\boldsymbol{N}^{u}\right]^{T}\left\{\boldsymbol{f}_{s}\right\} d s+\boldsymbol{f}_{p}$ & Force vector \\
$\{\boldsymbol{Q}\}=-\int_{V}\left[\boldsymbol{N}^{\phi}\right]^{T}\left\{\boldsymbol{q}_{v}\right\} d v-\int_{S}\left[\boldsymbol{N}^{\phi}\right]^{T}\left\{\boldsymbol{q}_{s}\right\} d s-\boldsymbol{q}_{p}$ & Electrical charge vector \\
\hline
\end{tabular}

\section{Formulation of the prismatic piezoelectric solid-shell finite elements}

The proposed prismatic piezoelectric solid-shell finite elements SHB6E and SHB15E are extensions of the linear and quadratic prismatic solid-shell elements SHB6 and SHB15, which were developed based on purely mechanical modeling. For the detailed formulations of the SHB6 and SHB15 elements, the interested reader may refer to references [46] and [47], respectively. The starting point for these piezoelectric extensions is the addition of one piezoelectric degree of freedom to each node of their mechanical finite element counterparts. The outline of these formulations is given in the following sections. 


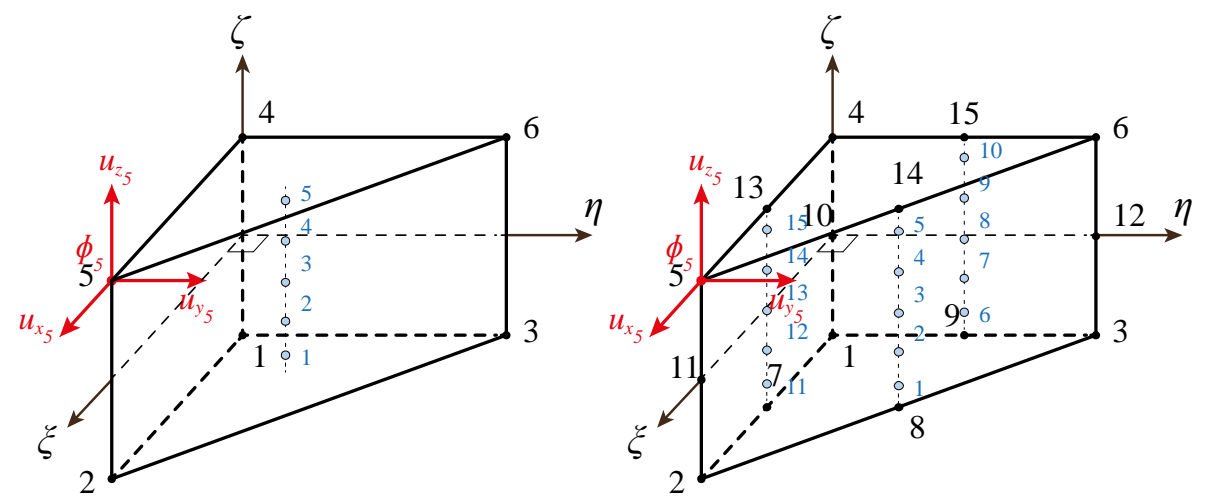

Figure 1. Schematic representation for the reference geometry of the SHB6E and SHB15E elements as well as for the location of their integration points in the case when the number of through-thickness integration points is $n_{\text {int }}=5$.

\subsection{Kinematics and interpolation}

The piezoelectric solid-shell finite elements SHB6E and SHB15E denote a six-node prismatic element and a fifteen-node one, respectively. These elements have at each of their nodes three displacement degrees of freedom as well as one electric degree of freedom. Similar to their mechanical counterparts SHB6 and SHB15, a special direction is chosen, designated as the "thickness", normal to the mean plane of these elements. Also, an in-plane reduced-integration rule is adopted, with $1 \times n_{\text {int }}$ integration points for the SHB6E element and $3 \times n_{\text {int }}$ for the SHB15E (see, e.g., Fig. 1 , in the particular case of $n_{\text {int }}=5$ ).

For the SHB6E and SHB15E elements, the spatial coordinates $x_{i}$ are related to the nodal coordinates $x_{i I}$ using linear and quadratic shape functions, respectively, as follows:

$$
x_{i}=x_{i I} N_{I}(\xi, \eta, \zeta)
$$

where $i$ represents the spatial directions and ranges from 1 to 3; while $I$ stands for the node number, which ranges from 1 to 6 , for the SHB6E element, and from 1 to 15 for the SHB15E. Likewise, the displacement field $u_{i}$ and potential field $\phi$ are related to the nodal displacements $u_{i I}$ and nodal potentials $\phi_{I}$, respectively, using the shape functions

$$
\left\{\begin{array}{l}
u_{i}=u_{i I} N_{I}^{u}(\xi, \eta, \zeta) \\
\phi=\phi_{I} N^{\phi}{ }_{I}(\xi, \eta, \zeta)
\end{array}\right.
$$

Note that in Eqs. (5) and (6) above, the convention of implied summation over the repeated index $I$ has been adopted. 


\subsection{Discrete gradient operators}

For both elements SHB6E and SHB15E, the corresponding gradient operators $\left[\mathbf{B}^{u}\right]$ and $\left[\mathbf{B}^{\phi}\right]$ can be written in the following compact form:

$$
\mathbf{B}^{u}=\left[\begin{array}{ccc}
\boldsymbol{b}_{1}^{T}+h_{\alpha, 1} \gamma_{\alpha}^{T} & \mathbf{0} & \mathbf{0} \\
\mathbf{0} & \boldsymbol{b}_{2}^{T}+h_{\alpha, 2} \gamma_{\alpha}^{T} & \mathbf{0} \\
\mathbf{0} & \mathbf{0} & \boldsymbol{b}_{3}^{T}+h_{\alpha, 3} \boldsymbol{\gamma}_{\alpha}^{T} \\
\boldsymbol{b}_{2}^{T}+h_{\alpha, 2} \gamma_{\alpha}^{T} & \boldsymbol{b}_{1}^{T}+h_{\alpha, 1} \boldsymbol{\gamma}_{\alpha}^{T} & \mathbf{0} \\
\boldsymbol{b}_{3}^{T}+h_{\alpha, 3} \gamma_{\alpha}^{T} & \mathbf{0} & \boldsymbol{b}_{1}^{T}+h_{\alpha, 1} \boldsymbol{\gamma}_{\alpha}^{T} \\
\mathbf{0} & \boldsymbol{b}_{3}^{T}+h_{\alpha, 3} \gamma_{\alpha}^{T} & \boldsymbol{b}_{2}^{T}+h_{\alpha, 2} \boldsymbol{\gamma}_{\alpha}^{T}
\end{array}\right] \quad ; \quad \mathbf{B}^{\phi}=\left[\begin{array}{l}
\boldsymbol{b}_{1}^{T}+h_{\alpha, 1} \boldsymbol{\gamma}_{\alpha}^{T} \\
\boldsymbol{b}_{2}^{T}+h_{\alpha, 2} \boldsymbol{\gamma}_{\alpha}^{T} \\
\boldsymbol{b}_{3}^{T}+h_{\alpha, 3} \boldsymbol{\gamma}_{\alpha}^{T}
\end{array}\right]
$$

where $\boldsymbol{b}_{i}^{T}, h_{\alpha, i}$ and $\boldsymbol{\gamma}_{\alpha}^{T}$ are given in full details in references [46, 47]. Note again that, in Eq. (7) and in what follows, the convention of implied summation over the repeated index $\alpha$ is adopted, with $\alpha$ ranging from 1 to 2, for the SHB6E element, and from 1 to 11 for the SHB15E.

Similar to the purely mechanics-based solid-shell element SHB15 (see, e.g., [47]), the benchmark tests performed with the piezoelectric solid-shell counterpart SHB15E did not reveal any particular locking and, accordingly, no specific enhanced assumed strain techniques have been applied to this quadratic solid-shell element. By contrast, the linear solid-shell version SHB6E suffers from various locking phenomena and, to alleviate these numerical pathologies, projection of its discrete gradient operator is undertaken following the assumed strain method. Note that the projection of the displacement-related discrete gradient operator $\mathbf{B}^{u}$ is performed in the same way as for the SHB6 element (see [46]), which leads to a similar form for the stiffness matrix $\mathbf{K}^{u}$. Hence, in the current work, special attention is paid to the effect of the assumed-strain projection on the piezoelectric and dielectric matrices $\mathbf{K}^{u \phi}$ and $\mathbf{K}^{\phi \phi}$.

\subsection{Assumed-strain projection for the $\mathrm{SHB6E}$}

Let us first recall that in Eq. (7), vectors $\boldsymbol{b}_{i}$ are defined by the following Hallquist form:

$$
\boldsymbol{b}_{i}=\boldsymbol{N}_{, i}^{u}(\mathbf{0})=\frac{\partial \boldsymbol{N}}{\partial x_{i \mid \xi=\eta=\zeta=0}} \quad i=1,2,3
$$

The assumed strain method proposed by Belytschko and Bindeman [48] is used here to reduce the above-mentioned locking phenomena. This projection technique starts by decomposing the discrete gradient operator $\mathbf{B}^{u}$ into two parts $\mathbf{B}^{u}{ }_{1}$ and $\mathbf{B}^{u}{ }_{2}$ as follows:

$$
\mathbf{B}^{u}=\mathbf{B}_{1}^{u}+\mathbf{B}_{2}^{u}
$$


where

$$
\begin{aligned}
\mathbf{B}^{u}{ }_{1} & =\left[\begin{array}{ccc}
\boldsymbol{b}_{1}^{T}+h_{\alpha, 1} \gamma_{\alpha}^{T} & \mathbf{0} & \mathbf{0} \\
\mathbf{0} & \boldsymbol{b}_{2}^{T}+h_{\alpha, 2} \gamma_{\alpha}^{T} & \mathbf{0} \\
\mathbf{0} & \mathbf{0} & \boldsymbol{b}_{3}^{T}+h_{\alpha, 3} \gamma_{\alpha}^{T} \\
\boldsymbol{b}_{2}^{T}+h_{\alpha, 2} \gamma_{\alpha}^{T} & \boldsymbol{b}_{1}^{T}+h_{\alpha, 1} \gamma_{\alpha}^{T} & \mathbf{0} \\
\mathbf{0} & \mathbf{0} & \mathbf{0} \\
\mathbf{0} & \mathbf{0} & \mathbf{0}
\end{array}\right] \\
\mathbf{B}_{2}^{u} & =\left[\begin{array}{ccc}
\mathbf{0} & \mathbf{0} & \mathbf{0} \\
\mathbf{0} & \mathbf{0} & \mathbf{0} \\
\mathbf{0} & \mathbf{0} & \mathbf{0} \\
\mathbf{0} & \mathbf{0} & \mathbf{0} \\
\boldsymbol{b}_{3}^{T}+h_{\alpha, 3} \gamma_{\alpha}^{T} & \mathbf{0} & \boldsymbol{b}_{1}^{T}+h_{\alpha, 1} \gamma_{\alpha}^{T} \\
\mathbf{0} & \boldsymbol{b}_{3}^{T}+h_{\alpha, 3} \gamma_{\alpha}^{T} & \boldsymbol{b}_{2}^{T}+h_{\alpha, 2} \gamma_{\alpha}^{T}
\end{array}\right]
\end{aligned}
$$

The first part $\mathbf{B}^{u}{ }_{1}$ contains the gradients in the mid-plane of the element (membrane terms of the deformation) as well as the normal strains, whereas the second part $\mathbf{B}_{2}{ }_{2}$ incorporates the gradients associated with the transverse shear strains. Then, using the $\mathrm{Hu}-\mathrm{Washizu}$ mixed variational principle, $\mathbf{B}^{u}{ }_{2}$ is projected onto a new operator $\overline{\mathbf{B}}_{2}{ }_{2}$, where $\overline{\mathbf{B}}^{u}{ }_{2}=\varepsilon \mathbf{B}^{u}{ }_{2}$, with $\varepsilon$ being a shear scaling factor. The stiffness matrix is finally computed as follows:

$$
\mathbf{K}_{e}^{u u}=\mathbf{K}^{u u}+\mathbf{K}_{2}^{u u}
$$

where

$$
\begin{aligned}
& \mathbf{K}^{u u}{ }_{1}=\int_{V_{e}} \mathbf{B}^{u}{ }_{1} T \cdot \mathbf{C} \cdot \mathbf{B}^{u}{ }_{1} d v \\
& \mathbf{K}^{u u}{ }_{2}=\int_{V_{e}} \mathbf{B}^{u T} \cdot \mathbf{C} \cdot \overline{\mathbf{B}}^{u}{ }_{2} d v+\int_{V_{e}} \overline{\mathbf{B}}_{2}{ }^{u T} \cdot \mathbf{C} \cdot \mathbf{B}^{u}{ }_{1} d v+\int_{V_{e}} \overline{\mathbf{B}}_{2}{ }_{2}^{T} \cdot \mathbf{C} \cdot \overline{\mathbf{B}}_{2}^{u} d v
\end{aligned}
$$

The first term $\mathbf{K}^{u u}$ above, which is not affected by projection, is evaluated using the integration points of the SHB6E element. With regard to the second term $\mathbf{K}^{u u}{ }_{2}$, which embodies all the projection, the particular choice of additive decomposition (9) along with the associated projection leads to a simplified form of this stiffness matrix component. Indeed, the cross-terms in the right-hand side of Eq. (12) vanish, and $\mathbf{K}_{2}^{u u}$ simply reduces to

$$
\mathbf{K}_{2}^{u u}=\int_{V_{e}} \overline{\mathbf{B}}_{2}^{u T} \cdot \mathbf{C} \cdot \overline{\mathbf{B}}_{2}^{u} d v
$$

For the complete details on the computation of the stiffness matrix and the associated projection, the interested reader may refer to reference [46]. 
For the derivation of the piezoelectric and dielectric matrices $\mathbf{K}^{u \phi}$ and $\mathbf{K}^{\phi \phi}$, a similar procedure is followed. However, the potential-related discrete gradient operator $\mathbf{B}^{\phi}$ is not projected, as it involves no shear components. Accordingly, the piezoelectric and dielectric matrices are computed as follows:

$$
\mathbf{K}_{e}^{u \phi}=\mathbf{K}_{1}^{u \phi}+\mathbf{K}^{u \phi}
$$

where

$$
\begin{aligned}
\mathbf{K}^{u \phi}{ }_{1} & =\int_{V_{e}} \mathbf{B}_{1}^{u T} \cdot \mathbf{e}^{T} \cdot \mathbf{B}^{\phi} d v \\
\mathbf{K}^{u \phi}{ }_{2} & =\int_{V_{e}} \overline{\mathbf{B}}_{2}^{u T} \cdot \mathbf{e}^{T} \cdot \mathbf{B}^{\phi} d v
\end{aligned}
$$

and

$$
\mathbf{K}_{e}^{\phi \phi}=-\int_{V_{e}} \mathbf{B}^{\phi T} \cdot \mathbf{K} \cdot \mathbf{B}^{\phi} d v
$$

Let us also recall that an improved plane-stress type constitutive law is adopted here for the SHB6E element, in order to enhance its immunity with regard to thickness locking. The elasticity matrix associated with this particular law is given by

for isotropic materials

$$
\mathbf{C}=\left[\begin{array}{cccccc}
\bar{\lambda}+2 \mu & \bar{\lambda} & 0 & 0 & 0 & 0 \\
\bar{\lambda} & \bar{\lambda}+2 \mu & 0 & 0 & 0 & 0 \\
0 & 0 & E & 0 & 0 & 0 \\
0 & 0 & 0 & \mu & 0 & 0 \\
0 & 0 & 0 & 0 & k \mu & 0 \\
0 & 0 & 0 & 0 & 0 & k \mu
\end{array}\right] \quad ; \quad \bar{\lambda}=\frac{E v}{1-v^{2}} \quad \text { and } \quad \mu=\frac{E}{2(1+v)}
$$

and for orthotropic materials

$$
\mathbf{C}=\left[\begin{array}{cccccc}
C_{11} & C_{12} & C_{13} & 0 & 0 & 0 \\
C_{12} & C_{22} & C_{23} & 0 & 0 & 0 \\
C_{13} & C_{23} & C_{33} & 0 & 0 & 0 \\
0 & 0 & 0 & C_{44} & 0 & 0 \\
0 & 0 & 0 & 0 & C_{55} & 0 \\
0 & 0 & 0 & 0 & 0 & C_{66}
\end{array}\right]
$$

where $E$ is the Young modulus, $v$ denotes the Poisson ratio, and $k=5 / 6$. 


\section{Numerical tests and discussions}

To evaluate the performance of the proposed piezoelectric solid-shell formulations, a selection of representative benchmark tests is conducted in static and vibration analysis, for multilayer beam, plate and shell structures. For all of the simulations, the mesh nomenclature adopted for prismatic elements is as follows: $\left(N_{1} \times N_{2} \times N_{3}\right) \times 2$ elements, where $N_{1}$ denotes the number of elements in the length direction, $N_{2}$ is the number of elements in the width direction, and $N_{3}$ is the number of elements in the thickness direction. Note that the multiplication by 2 of the number of in-plane elements $\left(N_{1} \times N_{2}\right)$ is due to the subdivision of each original hexahedron into two prisms. Note also that, for the proposed solid-shell elements SHB6E and SHB15E, two integration points along the thickness direction are sufficient for the following computations, as the corresponding benchmark tests do not involve material nonlinearities. However, it must be noted that, when nonlinear material behavior models enter into play, more through-thickness integration points are required (for instance, five through-thickness integration points are recommended when elasto-plastic constitutive models are used, see, e.g., reference [49]).

\subsection{Static benchmarks}

In the case of static analysis, the system of discretized equations (4) reduces to

$$
\left[\begin{array}{ll}
\mathbf{K}^{u u} & \mathbf{K}^{u \phi} \\
\mathbf{K}^{\phi u} & \mathbf{K}^{\phi \phi}
\end{array}\right]\left\{\begin{array}{l}
\boldsymbol{U} \\
\boldsymbol{\phi}
\end{array}\right\}=\left\{\begin{array}{l}
\boldsymbol{F} \\
\boldsymbol{Q}
\end{array}\right\}
$$

A set of three benchmark tests taken from the literature is investigated in the following sections. The first test is devoted to beams (bimorph and sandwich in extension and shear deformation mechanism, respectively), the second test is dedicated to the shape control of a plate with piezoelectric patches, and the third involves geometric nonlinearities through large deflection analysis of a shallow cylindrical sandwich blade.

\subsubsection{Extension and shear piezoelectric actuation mechanisms}

In this first benchmark test, we consider two configurations of cantilever sandwich beams, as illustrated in Fig. 2, which are actuatable in extension (a) and in shear (b), respectively. These tests represent excellent benchmark problems for their selectivity, and have become popular, as commonly studied in a number of literature works, including those of Zhang et Sun $[50,51]$ and Benjeddou et al. [52]. 

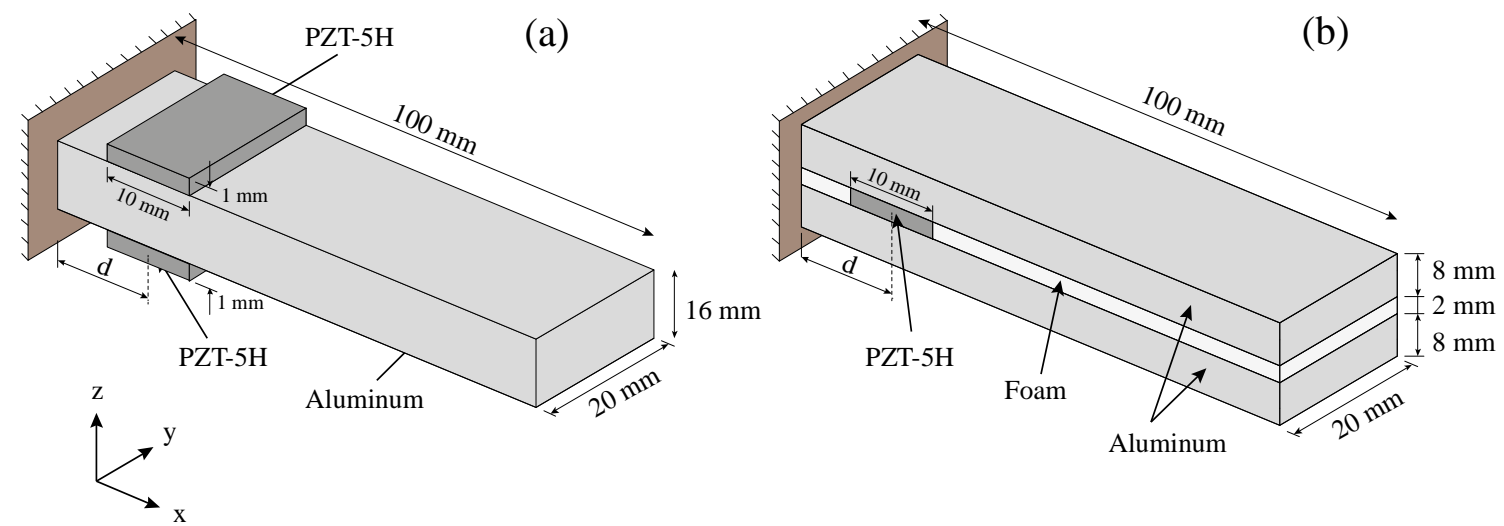

Figure 2. Cantilever sandwich beam, extension (a) and shear (b) actuation mechanisms.

The materials are polarized in the $z$-direction for the extension mechanism, and in the $x$ direction for the shear mechanism. In order to bend the beam, voltages are applied to the upper and lower surfaces of the piezoelectric layers, inducing electric bending forces. Thus, for the shear actuation mechanism, a voltage of $\Delta \phi=20 \mathrm{~V}$ is applied to the piezoelectric core, while for the extension actuation mechanism, voltages of $\Delta \phi= \pm 10 \mathrm{~V}$ are applied to the surface of the actuators. The material properties corresponding to this first benchmark test, which are taken from reference [50], are reported in Tab. 2. The numerical results obtained with the proposed SHB6E and SHB15E piezoelectric solid-shell elements are compared, on the one hand, with those taken from the literature [50-52] and, on the other hand, with those given by state-of-the-art ABAQUS elements that have equivalent geometry and kinematics, namely the C3D6E and C3D15E piezoelectric solid elements.

Table 2. Material properties used in the extension and shear mechanism models [50].

\begin{tabular}{ll}
\hline & $\rho=7730 \mathrm{Kg} \cdot \mathrm{m}^{-3}$ \\
& $\mathrm{C}_{11}=\mathrm{C}_{22}=126 \mathrm{GPa} ; \mathrm{C}_{33}=117 \mathrm{GPa}$ \\
& $\mathrm{C}_{12}=79.5 \mathrm{GPa} ; \mathrm{C}_{13}=\mathrm{C}_{23}=84.1 \mathrm{GPa}$ \\
& $\mathrm{C}_{44}=\mathrm{C}_{55}=\mathrm{C}_{66}=23.0 \mathrm{GPa}$ \\
& $\mathrm{e}_{15}=\mathrm{e}_{24}=17 \mathrm{C} / \mathrm{m}^{2}$ \\
& $\mathrm{e}_{31}=\mathrm{e}_{32}=-6.5 \mathrm{C} / \mathrm{m}^{2} ; \mathrm{e}_{33}=23.3 \mathrm{C} / \mathrm{m}^{2}$ \\
& $\kappa_{11}=\kappa_{22}=1.503 \mathrm{e}^{-8} \mathrm{~F} / \mathrm{m} ; \kappa_{33}=1.30 \mathrm{e}^{-8} \mathrm{~F} / \mathrm{m}$ \\
\hline Foam & $\rho=32 \mathrm{Kg} \cdot \mathrm{m}^{-3}$ \\
& $\mathrm{E}=35.3 \mathrm{MPa} ; v=0.38$ \\
\hline \multirow{2}{*}{ Aluminum } & $\rho=2690 \mathrm{Kg} \cdot \mathrm{m}^{-3}$ \\
& $\mathrm{E}=70.3 \mathrm{GPa} ; v=0.345$
\end{tabular}


Two cases with regard to the piezoelectric layer arrangement are considered. The first case corresponds to the situation when the piezoelectric layers cover the entire length of the beam; while in the second case, the position of the actuator varies in the $10-90 \mathrm{~mm}$ range.

First of all, a convergence analysis is conducted for all of the finite elements used in this study, in order to identify the mesh refinement required to achieve convergence. Fig. 3 shows the sensitivity of the results to mesh refinement, for all elements in the case of extension actuation mechanism. From these figures, it can be seen that, on the one hand, the proposed solid-shell elements SHB6E and SHB15E require much less degrees of freedom (dof) to converge towards the reference solution, as compared to their counterparts $\mathrm{C} 3 \mathrm{D} 6 \mathrm{E}$ and C3D15E, respectively. On the other hand, the proposed solid-shell elements are much less sensitive to mesh refinement in the thickness direction.
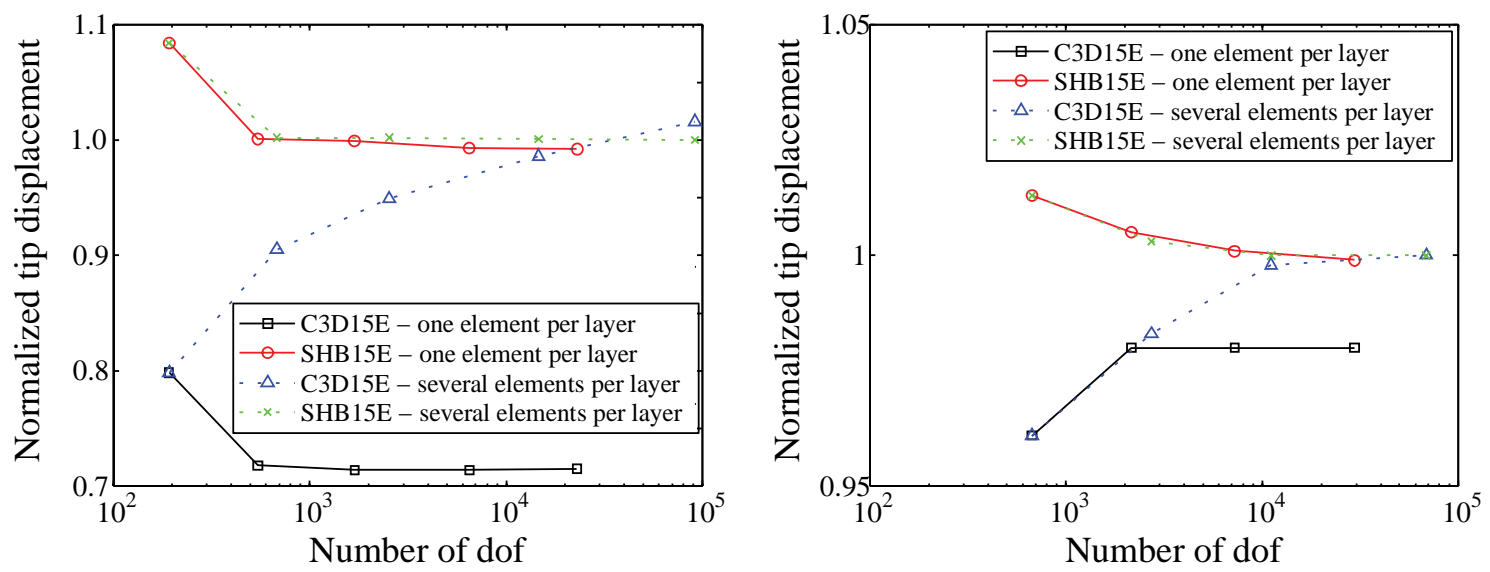

Figure 3. Convergence analysis in the case of cantilever sandwich beam with extension piezoelectric actuation mechanism.

After the above convergence study achieved, we proceed here with the analysis of the first case of piezoelectric layer arrangement (i.e., piezoelectric layers covering the entire length of the beam). The corresponding simulation results are reported in Fig. 4. Note that, in this first case and for the shear actuation mechanism, there is no rigid foam and, instead, the piezoelectric actuator covers the entire core layer. It appears from Fig. 4 that the results obtained with the proposed SHB6E and SHB15E elements are in excellent agreement with those given by ABAQUS elements. However, the literature results, which are obtained by 2D modeling, seem to overestimate the transverse deflection in the case when the beam is actuated by piezoelectric extension (see Fig. 4a). 
(a)

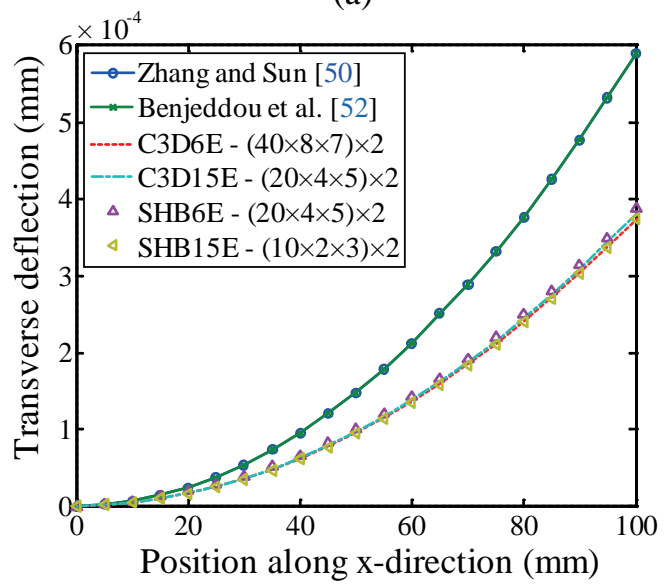

(b)

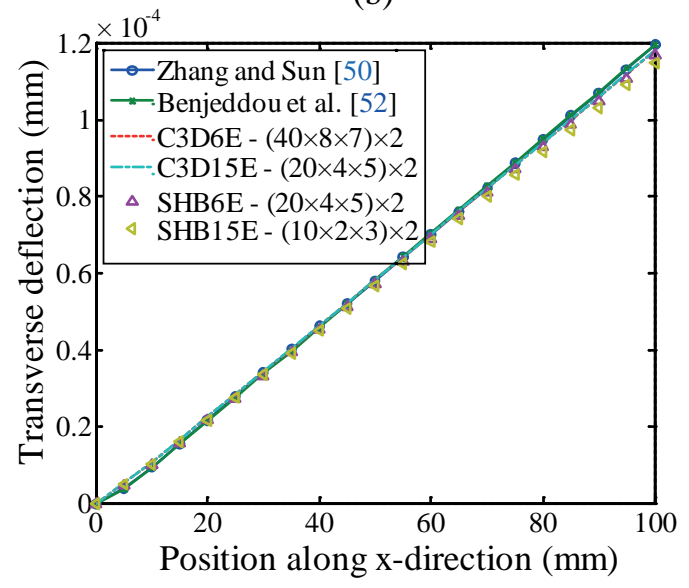

Figure 4. Transverse displacement of the beam for extension (a) and shear (b) mechanisms.

In the second case, where the actuator position varies in the $10-90 \mathrm{~mm}$ range, the deflection at the free edge is investigated for each position of the piezoelectric patches. Here again, the simulation results are compared with those taken from the literature (Benjeddou et al. [52] and Piefort [53], where only shear mechanism results are available) as well as with those given by the ABAQUS linear and quadratic piezoelectric solid elements C3D6E and C3D15E. From Fig. 5, it is observed that the results obtained with the SHB6E and SHB15E elements are in good agreement with those of the literature as well as those yielded by ABAQUS elements, for both actuation mechanisms. However, it is worth noting that the results obtained with the proposed solid-shell elements converge faster than those of existing conventional elements (i.e., relatively fewer elements are required with the SHB6E and SHB15E formulations to achieve convergence, as shown in Fig. 5).

(a)

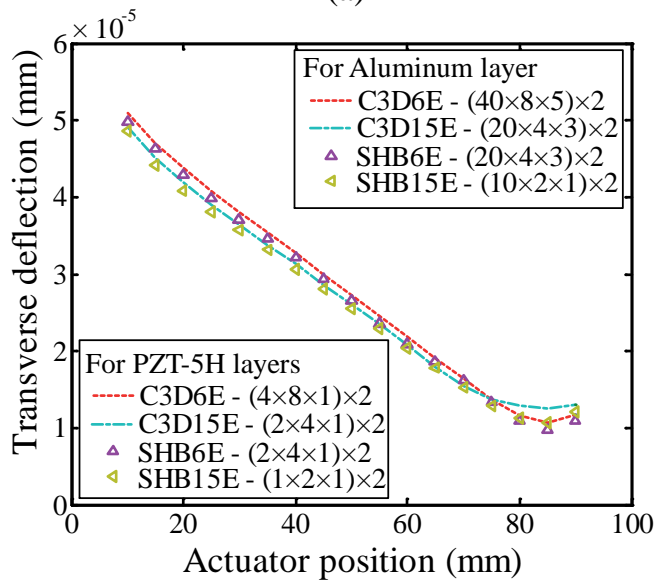

(b)

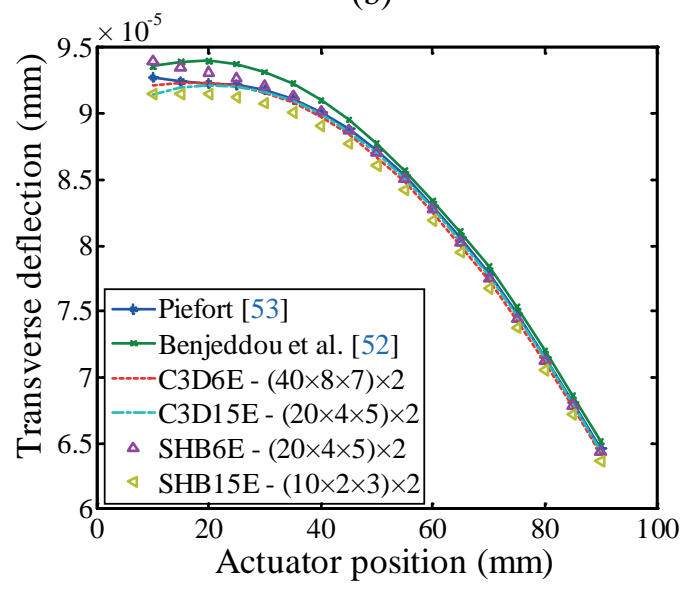

Figure 5. Tip displacement at the free edge of the beam for extension (a) and shear (b) mechanisms with different positions of piezoelectric patches. 


\subsubsection{Square plate with piezoelectric patch models}

One important advantage taken from the piezoelectric behavior is in the application to the shape control of structures. In order to show the interest of solid-shell finite elements in this type of modeling, we consider a square aluminum plate of $200 \times 200 \mathrm{~mm}^{2}$ with a thickness of 8 $\mathrm{mm}$. This plate is covered on both sides with four pairs of localized PZT-5H patches in various configurations, as shown in Fig. 6. The material properties corresponding to the current benchmark test as well as all subsequent tests are reported in Tab. 3. Each patch has dimensions of $40 \times 40 \mathrm{~mm}^{2}$ with a thickness of $1 \mathrm{~mm}$. The objective of this test is to investigate the optimal location of piezoelectric patches for shape control. With regard to loading conditions, the plate is subjected to a uniformly distributed load of $100 \mathrm{~N} . \mathrm{m}^{-2}$ over its entire surface. A constant voltage is then supplied incrementally to the piezoceramic actuators, which are polarized in opposite directions, until the plate is flattened. Fig. 7 shows the centerline deflection of the composite plate along the $x$-direction under different input voltages. The results provided by the solid-shell elements SHB6E and SHB15E are compared with those given by the ABAQUS solid elements C3D6E and C3D15E. On the whole, it appears that fewer degrees of freedom are required for the proposed solid-shell elements to achieve convergence, as compared to ABAQUS elements. As expected, the linear prismatic elements are generally stiffer due to locking effects. However, although stiffer, the SHB6E solid-shell element provides much better results compared to the $\mathrm{C} 3 \mathrm{D} 6 \mathrm{E}$, thanks to the applied assumed-strain projection.

Table 3. Material properties used for all benchmark tests (except the first test concerning the cantilever sandwich beam with extension and shear piezoelectric actuation mechanisms).

\begin{tabular}{ll}
\hline & $\rho=7500 \mathrm{Kg} \cdot \mathrm{m}^{-3}$ \\
& $\mathrm{C}_{11}=\mathrm{C}_{22}=127.2 \mathrm{GPa} ; \mathrm{C}_{33}=117.44 \mathrm{GPa}$ \\
& $\mathrm{C}_{12}=80.21 \mathrm{GPa} ; \mathrm{C}_{13}=\mathrm{C}_{23}=84.1 \mathrm{GPa}$ \\
& $\mathrm{C}_{44}=\mathrm{C}_{55}=\mathrm{C}_{66}=22.99 \mathrm{GPa}$ \\
& $\mathrm{e}_{15}=\mathrm{e}_{24}=17.0345 \mathrm{C} / \mathrm{m}^{2}$ \\
& $\mathrm{e}_{31}=\mathrm{e}_{32}=-6.6228 \mathrm{C} / \mathrm{m}^{2} ; \mathrm{e}_{33}=23.2403 \mathrm{C} / \mathrm{m}^{2}$ \\
& $\kappa_{11}=\kappa_{22}=1.509 \times 10^{-8} \mathrm{~F} / \mathrm{m} ; \kappa_{33}=1.269 \times 10^{-8} \mathrm{~F} / \mathrm{m}$ \\
\hline \multirow{2}{*}{ Aluminum $\quad$} & $\rho=2690 \mathrm{Kg} \cdot \mathrm{m}^{-3}$ \\
& $\mathrm{E}=70.3 \mathrm{GPa} ; v=0.345$
\end{tabular}



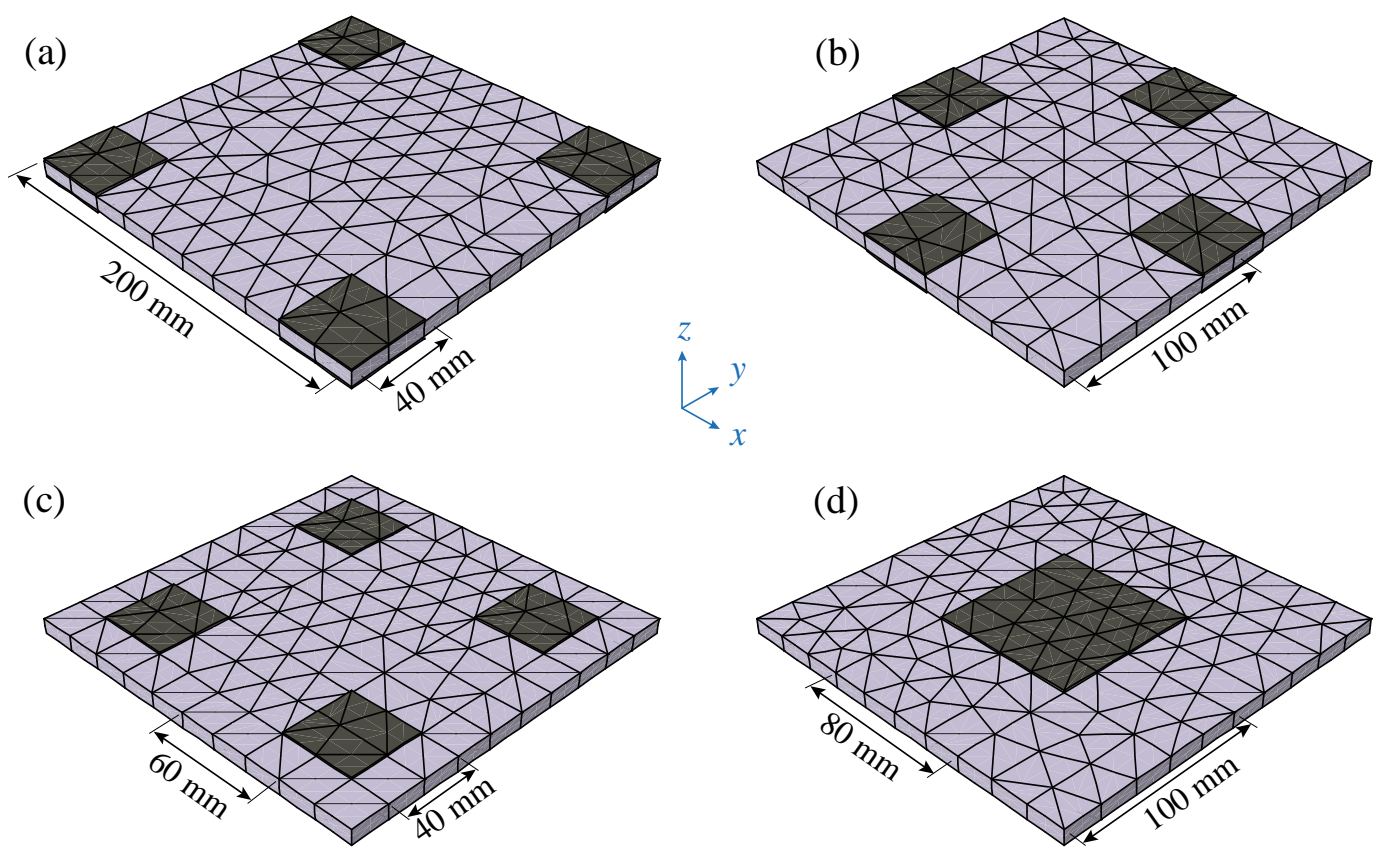

Figure 6. Square plate with piezoelectric patches. 
(a)

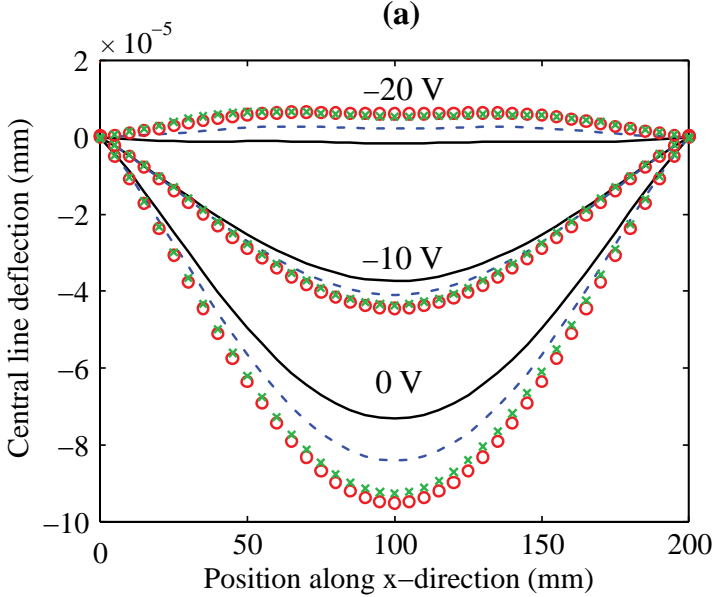

(c)

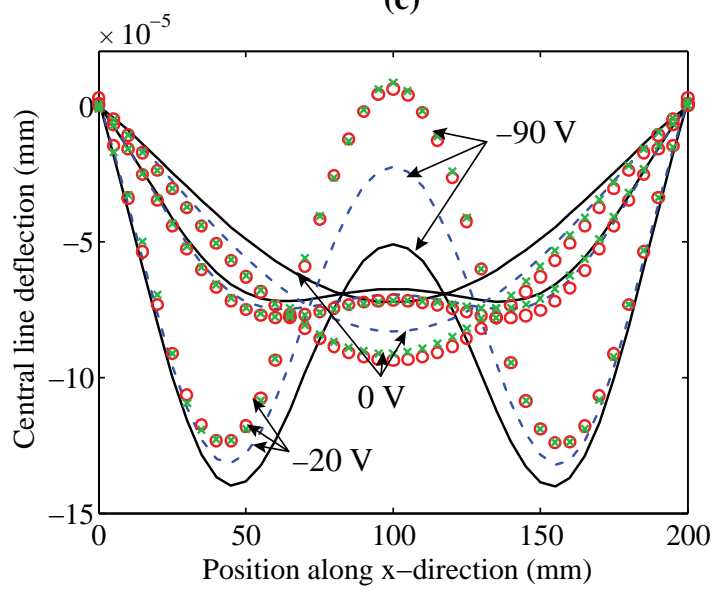

(b)

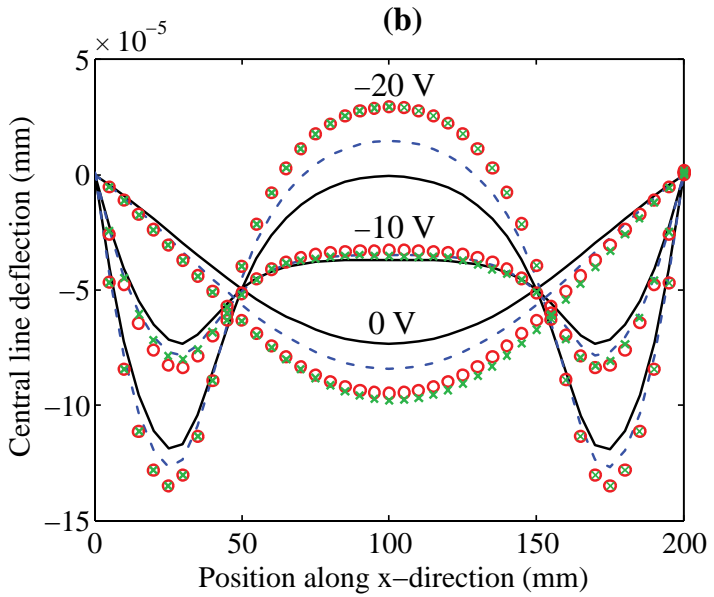

(d)

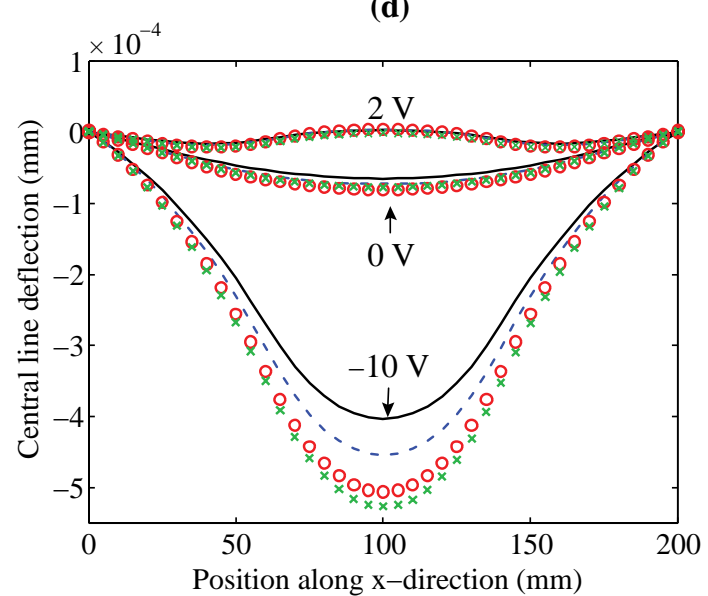

\begin{tabular}{|c|c|c|}
\hline For Aluminum layer & $\begin{array}{l}- \text { C3D6E - }(40 \times 40 \times 1) \times 2 \\
-\ldots \text { SHB6E - }(20 \times 20 \times 1) \times 2\end{array}$ & $\begin{array}{l}\circ \circ \circ \mathrm{C} 3 \mathrm{D} 15 \mathrm{E}-(20 \times 20 \times 1) \times 2 \\
\times \quad \times \text { SHB15E }-(10 \times 10 \times 1) \times 2\end{array}$ \\
\hline For PZT-5H layers & $\begin{array}{l}- \text { C3D6E - }(8 \times 8 \times 1) \times 2 \\
--- \text { SHB6E }-(4 \times 4 \times 1) \times 2\end{array}$ & $\begin{array}{l}\circ \circ \circ \mathrm{C} 3 \mathrm{D} 15 \mathrm{E}-(4 \times 4 \times 1) \times 2 \\
\times \quad \times \quad \mathrm{SHB} 15 \mathrm{E}-(2 \times 2 \times 1) \times 2\end{array}$ \\
\hline
\end{tabular}

Figure 7. Central line displacement for the square plate under uniform load and various values of voltage, for four different patch layouts.

In addition, the analysis of the plots in Fig. 7 shows that the (a) and (d) configurations are more effective in terms of shape control (plate flatness recovery). Note however that configuration (a) requires up to $-20 \mathrm{~V}$ by pair of patches to recover the initial shape of the plate, whereas only $2 \mathrm{~V}$ are sufficient for configuration (d).

\subsubsection{Shallow cylindrical sandwich blade}

In order to assess the capabilities of the proposed solid-shell elements in geometric nonlinear analysis, a cantilever shallow cylindrical sandwich shell with $300 \mathrm{~mm}$ for both of its straight and curved edges, as depicted in Fig. 8, is considered. A similar model has been proposed by Kioua and Mirza [54], but no comparison with available finite element 
technologies was attempted. Here again, the host shell is made in aluminum and has a thickness of $2.50 \mathrm{~mm}$. This shell is entirely covered on both sides with a thin PZT-5H layer of $0.25 \mathrm{~mm}$ thickness polarized across the thickness. A voltage of $50 \mathrm{~V}$ is applied to each piezoelectric layer (the internal faces are connected to ground, while $50 \mathrm{~V}$ is applied to the external faces) to induce bending actuation. Three ratios $R / b$ are considered ( $R / b=\{1,10, \infty\})$. The considered layup configuration for the laminated shell causes high stiffness coupling and, consequently, also generates a twisting deformation. The deflections along paths A, B and C, as depicted in Fig. 8, are investigated.

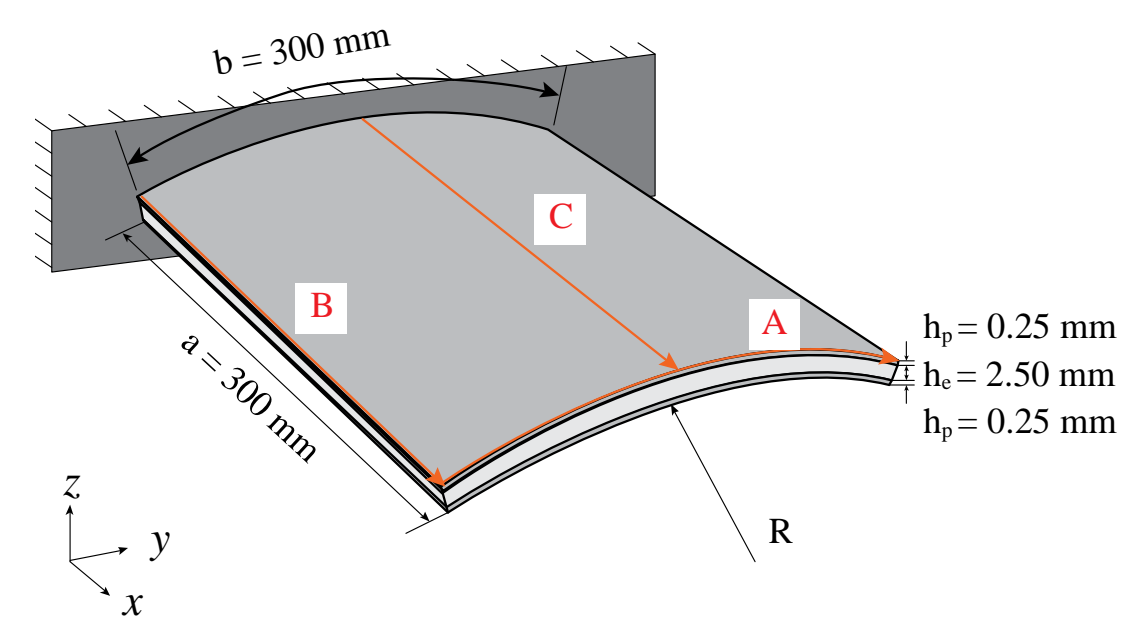

Figure 8. Cantilever curved sandwich shell. 

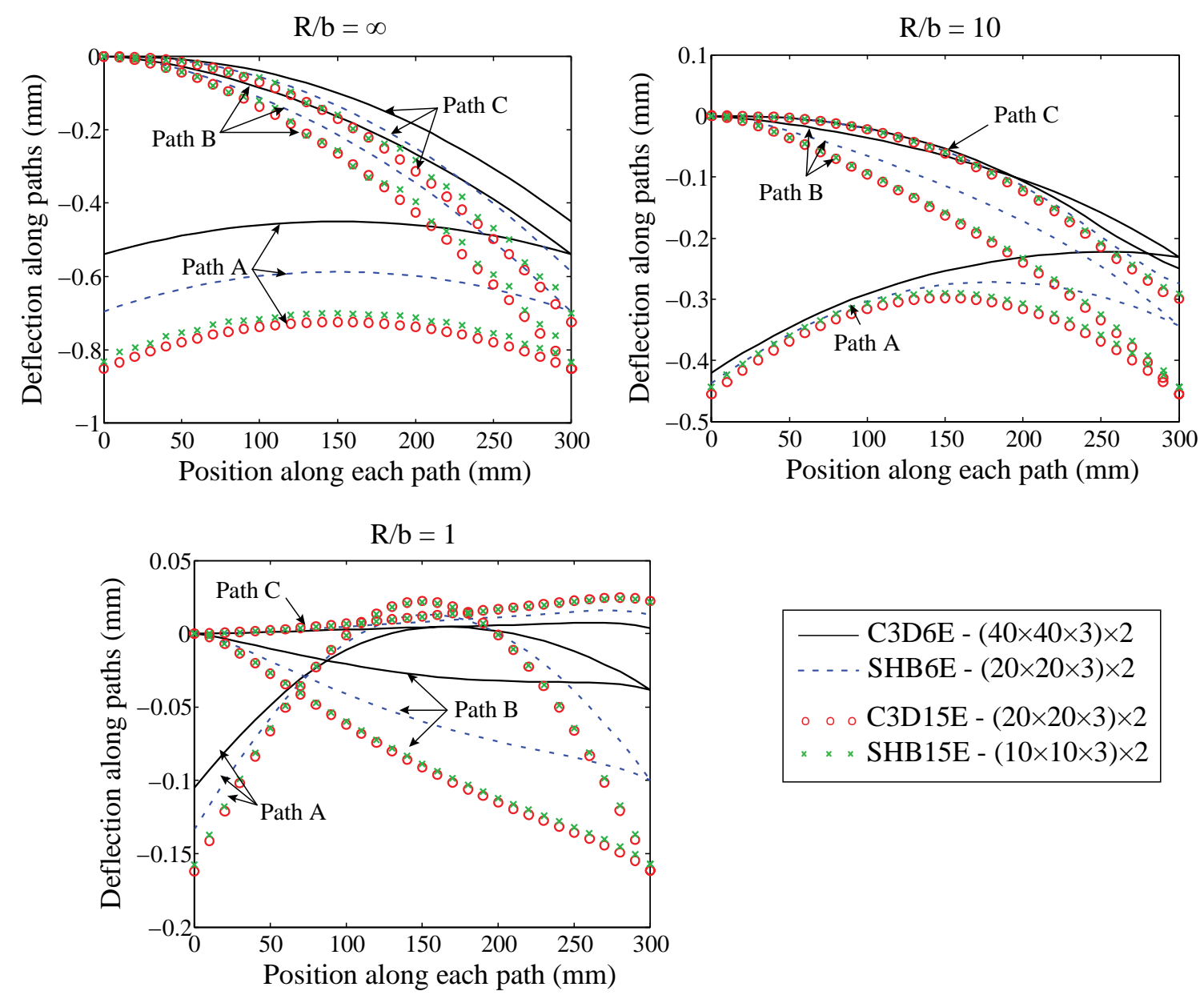

Figure 9. Deflection along paths A, B and C for the clamped curved sandwich shell, for different curvatures $R / b$.

Here again, the results provided by the solid-shell finite elements SHB6E and SHB15E are compared to those given by the ABAQUS solid elements C3D6E and C3D15E (see Fig. 9). It appears, once again, that a good agreement is achieved with respect to the reference results, which highlights the benefit of using the proposed elements SHB6E and SHB15E in this kind of analysis. However, a phenomenon that is quite common with triangular-based elements, the linear prismatic formulations SHB6E and C3D6E exhibit stiffer behavior due to locking. As previously revealed, despite its relative stiffness, the solid-shell element SHB6E provides better results than its counterpart C3D6E, due to its treatment against locking via the assumed-strain method.

With these preliminary set of static tests performed, focus is placed in the following sections on free vibration modeling of sandwich structures that contain piezoelectric layers, in order to evaluate the performance of the proposed solid-shell formulations.

\subsection{Vibration test problems}

In the case of free vibration analysis, the system of discretized equations (4) becomes 


$$
\left(\left[\begin{array}{ll}
\mathbf{K}^{u u} & \mathbf{K}^{u \phi} \\
\mathbf{K}^{\phi u} & \mathbf{K}^{\phi \phi}
\end{array}\right]-\omega^{2}\left[\begin{array}{cc}
\mathbf{M}^{u u} & \mathbf{0} \\
\mathbf{0} & \mathbf{0}
\end{array}\right]\right)\left\{\begin{array}{l}
\boldsymbol{U} \\
\boldsymbol{\phi}
\end{array}\right\}=\left\{\begin{array}{l}
\mathbf{0} \\
\mathbf{0}
\end{array}\right\}
$$

In the following sections, a set of free vibration tests both in open-circuit and short-circuit configurations will be carried out on beam, plate and shell structures.

\subsubsection{Sandwich plate}

In this first example of this category of benchmark problems, we investigate the free vibration response of a simply supported sandwich plate. The plate consists of two piezoelectric faces, in PZT-5H material polarized along the thickness, covering a core made of aluminum with a varying thickness. The piezoelectric faces have a thickness of $1 \mathrm{~mm}$, while the other geometric dimensions are shown in Fig. 10. Different thicknesses for the aluminum core are considered, according to a geometric ratio $r$, in order to analyze the sensitivity to thickness reduction of the results given by the proposed solid-shell elements. The first three free vibration frequencies are investigated in both short-circuit and open-circuit configurations and are reported in Tab. 4.

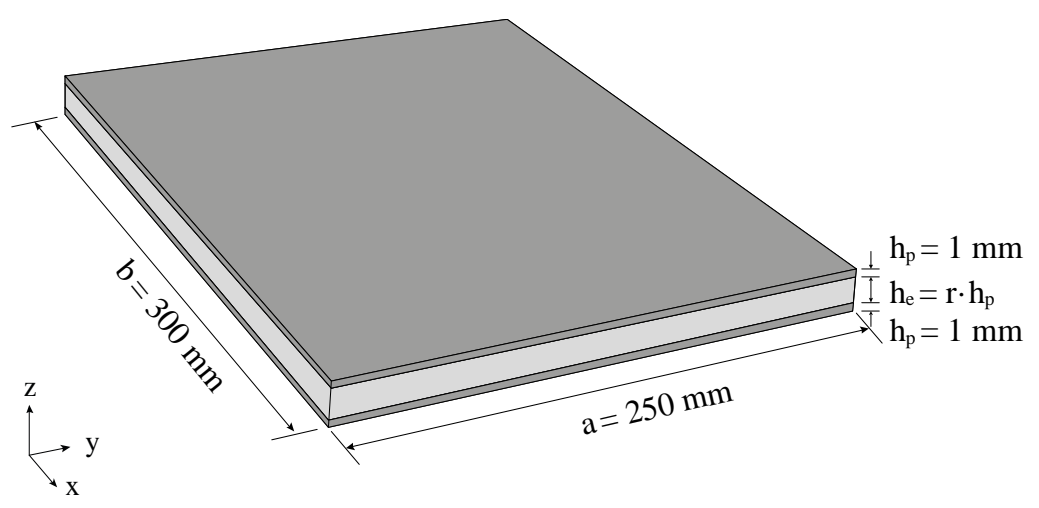

Figure 10. Simply supported rectangular sandwich plate.

According to Tab. 4, the results obtained with the solid-shell finite elements SHB6E and SHB15E are in good agreement with those of the reference element C3D15E. Here again, the linear prismatic elements are stiffer, which is not surprising for linear triangular-based elements that are known to be more sensitive to locking. It should be noted, however, that fewer degrees of freedom are required for the proposed solid-shell elements, as compared to their counterparts with the same kinematics. 
Table 4. First three natural frequencies for the rectangular sandwich plate.

\begin{tabular}{lcccc}
\hline & $\begin{array}{c}\text { C3D6E } \\
(48 \times 40 \times 3) \times 2\end{array}$ & $\begin{array}{c}\text { SHB6E } \\
(24 \times 20 \times 3) \times 2\end{array}$ & $\begin{array}{c}\text { C3D15E } \\
(24 \times 20 \times 3) \times 2\end{array}$ & $\begin{array}{c}\text { SHB15E } \\
(12 \times 10 \times 3) \times 2\end{array}$ \\
\hline Short circuit & & & & \\
\cline { 2 - 5 } $\mathrm{r}=1$ & 209.95 & 182.96 & 180.73 & 181.09 \\
& 389.70 & 338.22 & 329.04 & 331.56 \\
& 461.53 & 401.14 & 387.52 & 391.42 \\
\cline { 2 - 5 } $\mathrm{r}=5$ & 551.75 & 526.53 & 506.01 & 510.77 \\
& 1009.4 & 960.78 & 918.04 & 929.64 \\
& 1192.3 & 1138.5 & 1082.1 & 1096.0 \\
$\mathrm{r}=20$ & 1879.6 & 1593.9 & 1679.4 & 1737.4 \\
& 3302.8 & 2778.4 & 2961.8 & 3034.0 \\
\hline \multirow{3}{*}{ Open circuit } & 3800.8 & 3214.9 & 3387.1 & 3483.2 \\
\hline \multirow{3}{*}{$\mathrm{r}=1$} & & & & \\
& 236.40 & 211.24 & 210.95 & 211.38 \\
& 433.75 & 385.32 & 381.13 & 383.74 \\
$\mathrm{r}=5$ & 513.55 & 457.68 & 448.87 & 453.82 \\
\hline \multirow{3}{*}{$\mathrm{r}=20$} & 601.43 & 575.04 & 560.77 & 565.87 \\
& 1100.5 & 1048.1 & 1019.1 & 1030.5 \\
& 1300.7 & 1243.5 & 1201.9 & 1217.6 \\
\hline \multirow{2}{*}{} & 1941.9 & 1639.6 & 1756.6 & 1806.4 \\
& 3406.8 & 2847.5 & 3085.8 & 3152.3 \\
& 3920.1 & 3295.8 & 3527.9 & 3622.0 \\
\hline
\end{tabular}

In the following sections, free vibration analysis of shell structures provided with piezoelectric materials will be conducted. The aim is to assess the performance and reliability of the proposed solid-shell elements in the modeling of sandwich structures involving geometric nonlinearities.

\subsubsection{Hemispherical sandwich shell with a hole}

The last benchmark test in this category is concerned with a doubly curved sandwich shell structure. This consists of a hemispherical shell, with an $18^{\circ}$ hole and a mean radius of 200 $\mathrm{mm}$, as depicted in Fig. 11. The host structure is made of aluminum material and has a thickness of $1.50 \mathrm{~mm}$. This hemispherical shell is entirely covered on both sides with a thin PZT-5H layer, which is polarized across its thickness of $0.25 \mathrm{~mm}$. The shell structure is clamped over the entire holed face. The current analysis consists in investigating the first five modes in both short-circuit and open-circuit configurations, which are illustrated in Fig. 12. The results in terms of the corresponding natural frequencies (first five natural frequencies) are summarized in Tab. 5.

As previously done, the results obtained with the proposed solid-shell formulations are compared in Tab. 5 with their ABAQUS counterparts, which are based on the same geometry and kinematics. From Tab. 5, it appears that the results provided by the developed solid-shell elements are in good agreement with the reference solution given by the C3D15E ABAQUS 
quadratic piezoelectric element. In the same way as revealed before, the linear prismatic elements exhibit some excessive stiffness in this severe benchmark test. However, as discussed previously, the results given by the proposed linear prismatic solid-shell element SHB6E are much better than those yielded by its ABAQUS counterpart C3D6E. This enhanced behavior for the SHB6E element with regard to locking is made possible thanks to the implementation of an assumed-strain projection in its formulation.

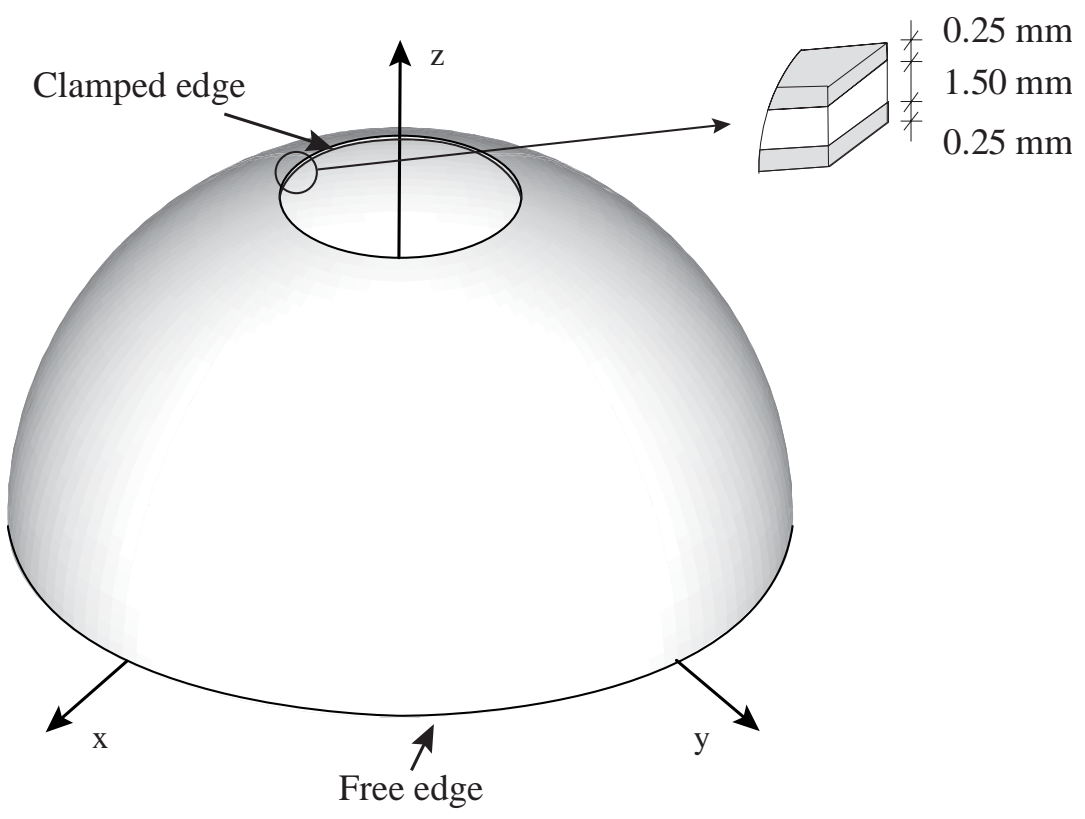

Figure 11. Hemispherical sandwich shell with a hole.
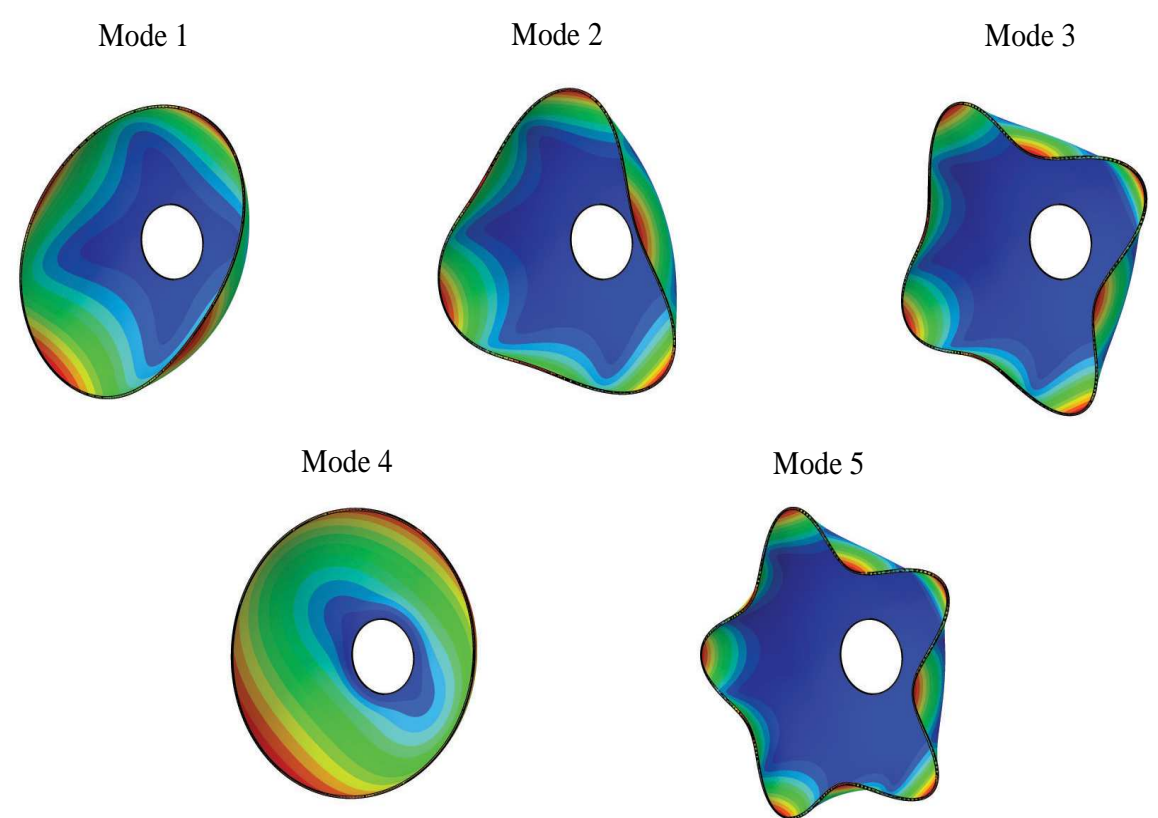

Mode 5

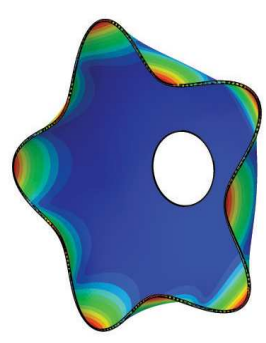

Figure 12. First five vibration modes for the hemispherical sandwich shell with a hole. 
Table 5. First five natural frequencies for the hemispherical sandwich shell with a hole.

\begin{tabular}{|c|c|c|c|c|}
\hline & $\begin{array}{c}\text { C3D6E } \\
(200 \times 50 \times 3) \times 2 \\
\end{array}$ & $\begin{array}{c}\text { SHB6E } \\
(100 \times 25 \times 3) \times 2 \\
\end{array}$ & $\begin{array}{c}\text { C3D15E } \\
(80 \times 20 \times 3) \times 2 \\
\end{array}$ & $\begin{array}{c}\text { SHB15E } \\
(40 \times 20 \times 3) \times 2\end{array}$ \\
\hline \multicolumn{5}{|l|}{ Short circuit } \\
\hline & 135.82 & 99.329 & 74.953 & 75.422 \\
\hline & 297.31 & 186.32 & 114.32 & 116.25 \\
\hline & 321.54 & 247.72 & 215.84 & 214.79 \\
\hline & 606.47 & 458.40 & 287.09 & 288.61 \\
\hline & 926.92 & 660.67 & 344.76 & 344.53 \\
\hline \multicolumn{5}{|l|}{ Open circuit } \\
\hline & 137.09 & 100.98 & 76.354 & 76.817 \\
\hline & 300.36 & 188.36 & 115.01 & 119.94 \\
\hline & 324.34 & 248.77 & 217.62 & 222.17 \\
\hline & 612.80 & 461.90 & 290.80 & 297.02 \\
\hline & 938.55 & 661.42 & 348.56 & 346.42 \\
\hline
\end{tabular}

\section{Conclusions}

In the current contribution, two new prismatic piezoelectric solid-shell finite elements have been developed. These finite element technologies consist of a six-node prism, denoted as SHB6E, and a fifteen-node prism, designated as SHB15E. These formulations are based on purely three-dimensional kinematics and, accordingly, the resulting finite elements have at each of their nodes three translational degrees of freedom and one electric degree of freedom. To provide these elements with some desirable shell features, and to alleviate locking effects, an in-plane reduced-integration scheme is adopted, with a user-defined number of integration points along the thickness direction. The constitutive law is also expressed in a local physical coordinate system, which is attached to the element mid-plane, in order to enhance immunity with regard to thickness locking.

The performances as well as the benefits of these new element formulations have been assessed through a set of selective and representative benchmark problems both in static and vibration analysis. The simulation results obtained by the newly devised solid-shell elements have been compared with reference solutions taken from the literature and also with state-ofthe-art finite elements available in ABAQUS. Among the latter, the quadratic piezoelectric element C3D15E is often taken as reference. In all of the benchmark tests, the quadratic solid-shell element SHB15E has shown better performance than its C3D15E counterpart from ABAQUS, while systematically requiring less degrees of freedom for the same accuracy. In the same way, the linear solid-shell element SHB6E provided better results than its conventional counterpart C3D6E, although both exhibiting some over-stiffness due to locking in situations of severe nonlinearities. In future work, it would be interesting to further improve the performance of the SHB6E element, by using for instance other advanced enhanced strain methods. 


\section{References}

[1] K. Takayoshi, F. Takafumi, H. Takayoshi, A. Takeo, M. Nobuyoshi, A. Satoru, T. Kohtaro, Active vibration control of frame structures with smart structures using piezoelectric actuators (Vibration control by control of bending moments of columns), Smart Materials and Structures, 6 (1997) 448-456.

[2] Z.-c. Qiu, X.-m. Zhang, H.-x. Wu, H.-h. Zhang, Optimal placement and active vibration control for piezoelectric smart flexible cantilever plate, Journal of Sound and Vibration, 301 (2007) 521-543.

[3] S. Belouettar, L. Azrar, E.M. Daya, V. Laptev, M. Potier-Ferry, Active control of nonlinear vibration of sandwich piezoelectric beams: A simplified approach, Computers \& Structures, 86 (2008) 386-397.

[4] C. Chee, L. Tong, G.P. Steven, Piezoelectric actuator orientation optimization for static shape control of composite plates, Composite Structures, 55 (2002) 169-184.

[5] Q. Nguyen, L. Tong, Shape control of smart composite plate with non-rectangular piezoelectric actuators, Composite Structures, 66 (2004) 207-214.

[6] Q. Nguyen, L. Tong, Voltage and evolutionary piezoelectric actuator design optimisation for static shape control of smart plate structures, Materials \& Design, 28 (2007) 387-399.

[7] X. Zhang, J. Lu, Y. Shen, Active noise control of flexible linkage mechanism with piezoelectric actuators, Computers \& Structures, 81 (2003) 2045-2051.

[8] S.M. Hasheminejad, M. Rajabi, Scattering and active acoustic control from a submerged piezoelectric-coupled orthotropic hollow cylinder, Journal of Sound and Vibration, 318 (2008) 50-73.

[9] A.S. Wixom, M.J. Anderson, D.F. Bahr, D.J. Morris, A new acoustic transducer with a pressure-deformed piezoelectric diaphragm, Sensors and Actuators A: Physical, 179 (2012) 204-210.

[10] H.F. Olson, Electronic control of noise, vibration and reverberation, Journal of the Acoustical Society of America, 28 (1956) 972-976.

[11] G. Park, H. Cudney, D. Inman, Impedance-based health monitoring of civil structural components, Journal of Infrastructure Systems, 6 (2000) 153-160.

[12] W.H. Duan, Q. Wang, S.T. Quek, Applications of Piezoelectric Materials in Structural Health Monitoring and Repair: Selected Research Examples, Materials, 3 (2010) 5169-5194.

[13] Y.K. An, M.K. Kim, H. Sohn, Piezoelectric transducers for assessing and monitoring civil infrastructures, Sensor Technologies for Civil Infrastructures, 1 (2014) 86-120.

[14] H. Allik, T.J.R. Hughes, Finite element method for piezoelectric vibration, International Journal for Numerical Methods in Engineering, 2 (1970) 151-157. 
[15] D.A. Saravanos, P.R. Heyliger, Coupled Layerwise Analysis of Composite Beams with Embedded Piezoelectric Sensors and Actuators, Journal of Intelligent Material Systems and Structures, 6 (1995) 350-363.

[16] A. Benjeddou, Advances in piezoelectric finite element modeling of adaptive structural elements: a survey, Computers \& Structures, 76 (2000) 347-363.

[17] T. Rödig, A. Schönecker, G. Gerlach, A survey on piezoelectric ceramics for generator applications, Journal of the American Ceramic Society, 93 (2010) 901-912.

[18] J. Peng, A survey of modeling and control of piezoelectric actuators, Modern Mechanical Engineering, 3 (2013) 1-20.

[19] D.H. Robbins, J.N. Reddy, Analysis of piezoelectrically actuated beams using a layerwise displacement theory, Computers \& Structures, 41 (1991) 265-279.

[20] J.-H. Han, I. Lee, Analysis of composite plates with piezoelectric actuators for vibration control using layerwise displacement theory, Composites Part B: Engineering, 29 (1998) 621-632.

[21] W.-S. Hwang, H.C. Park, Finite element modeling of piezoelectric sensors and actuators, AIAA Journal, 31 (1993) 930-937.

[22] G.R. Liu, X.Q. Peng, K.Y. Lam, J. Tani, Vibration control simulation of laminated composite plates with integrated piezoelectrics, Journal of Sound and Vibration, 220 (1999) 827-846.

[23] J.M. Simões Moita, I.F.P. Correia, C.M. Mota Soares, C.A. Mota Soares, Active control of adaptive laminated structures with bonded piezoelectric sensors and actuators, Computers \& Structures, 82 (2004) 1349-1358.

[24] R.D. Mindlin, Forced thickness $\square$ shear and flexural vibrations of piezoelectric crystal plates, Journal of Applied Physics, 23 (1952) 83-88.

[25] J.M.S. Moita, C.M.M. Soares, C.A.M. Soares, Active control of forced vibrations in adaptive structures using a higher order model, Composite Structures, 71 (2005) 349355.

[26] T.S. Plagianakos, E.G. Papadopoulos, Higher-order 2-D/3-D layerwise mechanics and finite elements for composite and sandwich composite plates with piezoelectric layers, Aerospace Science and Technology, 40 (2015) 150-163.

[27] A. Mannini, P. Gaudenzi, Multi-layer higher-order finite elements for the analysis of free-edge stresses in piezoelectric actuated laminates, Composite Structures, 63 (2004) 263-270.

[28] S.M. Shiyekar, T. Kant, Higher order shear deformation effects on analysis of laminates with piezoelectric fibre reinforced composite actuators, Composite Structures, 93 (2011) 3252-3261. 
[29] S. Kapuria, P.C. Dumir, A. Ahmed, N. Alam, Finite element model of efficient zigzag theory for static analysis of hybrid piezoelectric beams, Computational Mechanics, 34 (2004) 475-483.

[30] S. Kapuria, A. Ahmed, P.C. Dumir, An efficient coupled zigzag theory for dynamic analysis of piezoelectric composite and sandwich beams with damping, Journal of Sound and Vibration, 279 (2005) 345-371.

[31] S. Kapuria, N. Alam, Efficient layerwise finite element model for dynamic analysis of laminated piezoelectric beams, Computer Methods in Applied Mechanics and Engineering, 195 (2006) 2742-2760.

[32] S. Kapuria, S.D. Kulkarni, Efficient finite element with physical and electric nodes for transient analysis of smart piezoelectric sandwich plates, Acta Mechanica, 214 (2010) 123-131.

[33] H. Boudaoud, E.M. Daya, S. Belouettar, L. Duigou, M. Potier-Ferry, Damping analysis of beams submitted to passive and active control, Engineering Structures, 31 (2009) 322-331.

[34] L. Azrar, S. Belouettar, J. Wauer, Nonlinear vibration analysis of actively loaded sandwich piezoelectric beams with geometric imperfections, Computers \& Structures, 86 (2008) 2182-2191.

[35] T. Weller, C. Licht, Asymptotic modeling of thin piezoelectric plates, Annals of Solid and Structural Mechanics, 1 (2010) 173-188.

[36] T. Weller, C. Licht, Asymptotic modeling of piezoelectric plates with electric field gradient, Comptes Rendus Mécanique, 340 (2012) 405-410.

[37] K.Y. Sze, L.Q. Yao, A hybrid stress ANS solid-shell element and its generalization for smart structure modelling. Part I-solid-shell element formulation, International Journal for Numerical Methods in Engineering, 48 (2000) 545-564.

[38] K.Y. Sze, L.Q. Yao, S. Yi, A hybrid stress ANS solid-shell element and its generalization for smart structure modelling. Part II-smart structure modelling, International Journal for Numerical Methods in Engineering, 48 (2000) 565-582.

[39] X.G. Tan, L. Vu-Quoc, Optimal solid-shell element for large-deformable composite structures with piezoelectric layers and active vibration control, International Journal for Numerical Methods in Engineering, 64 (2005) 1981-2013.

[40] S. Klinkel, W. Wagner, A geometrically non-linear piezoelectric solid shell element based on a mixed multi-field variational formulation, International Journal for Numerical Methods in Engineering, 65 (2006) 349-382.

[41] S. Klinkel, W. Wagner, A piezoelectric solid shell element based on a mixed variational formulation for geometrically linear and nonlinear applications, Computers \& Structures, 86 (2008) 38-46.

[42] S. Zheng, X. Wang, W. Chen, The formulation of a refined hybrid enhanced assumed strain solid shell element and its application to model smart structures containing 
distributed piezoelectric sensors/actuators, Smart Materials and Structures, 13 (2004) 43-50.

[43] G.M. Kulikov, S.V. Plotnikova, Geometrically exact four-node piezoelectric solidshell element, Mechanics of Advanced Materials and Structures, 15 (2008) 199-207.

[44] G.M. Kulikov, S.V. Plotnikova, The use of 9-parameter shell theory for development of exact geometry 12-node quadrilateral piezoelectric laminated solid-shell elements, Mechanics of Advanced Materials and Structures, 22 (2015) 490-502.

[45] F. Kpeky, Formulation et modélisation des vibrations par éléments finis de type solide-coque : application aux structures sandwichs viscoélastiques et piézoélectriques, PhD Thesis, Université de Lorraine, 2016.

[46] V.-D. Trinh, F. Abed-Meraim, A. Combescure, A new assumed strain solid-shell formulation "SHB6" for the six-node prismatic finite element, Journal of Mechanical Science and Technology, 25 (2011) 2345-2364.

[47] F. Abed-Meraim, V.D. Trinh, A. Combescure, New quadratic solid-shell elements and their evaluation on linear benchmark problems, Computing, 95 (2013) 373-394.

[48] T. Belytschko, L.P. Bindeman, Assumed strain stabilization of the eight node hexahedral element, Computer Methods in Applied Mechanics and Engineering, 105 (1993) 225-260.

[49] F. Abed-Meraim, A. Combescure, An improved assumed strain solid-shell element formulation with physical stabilization for geometric non-linear applications and elastic-plastic stability analysis, International Journal for Numerical Methods in Engineering, 80 (2009) 1640-1686.

[50] X.D. Zhang, C.T. Sun, Formulation of an adaptive sandwich beam, Smart Materials and Structures, 5 (1996) 814-823.

[51] C.T. Sun, X.D. Zhang, Use of thickness-shear mode in adaptive sandwich structures, Smart Materials and Structures, 4 (1995) 202-206.

[52] A. Benjeddou, M. Trindade, R. Ohayon, A unified beam finite element model for extension and shear piezoelectric actuation mechanisms, Journal of Intelligent Material Systems and Structures, 8 (1997) 1012-1025.

[53] V. Piefort, Finite element modeling of piezoelectric active structures, $\mathrm{PhD}$ Thesis, University of Brussels, 2001.

[54] H. Kioua, S. Mirza, Piezoelectric induced bending and twisting of laminated composite shallow shells, Smart Materials and Structures, 9 (2000) 476-484. 